\title{
How does Basic Research Promote the Innovation for Patented Invention: a Measuring of NPC and Technology Coupling
}

\author{
Jie Gui ${ }^{1, a,{ }^{*}}$, Chang-Qing Yao ${ }^{2, b}$, Wen Zeng ${ }^{3, c}$, Zhao-Feng Zhang ${ }^{4, d}$ \\ 1,2,3,4 Institute of Scientific and Technical Information of China, Beijing, 100038 China \\ aguij@istic.ac.cn, byaocq@istic.ac.cn, czengw@istic.ac.cn, ${ }^{\mathrm{d}}$ zhangzf@istic.ac.cn \\ *Corresponding author
}

Keywords: Patent analysis, NPC measuring, Technology coupling, Patent evaluation.

\begin{abstract}
When a new technology is invented, it may absorb new knowledge from basic research. But how to evaluate the affection of basic research on technological invention and innovation accurately is difficult. The paper constructs a model for measuring the relationship between basic research and patented invention by quantitative analysis. The research introduces the concept of technology coupling which can be used for measuring technological complexity in the process of patented invention. The paper develops an empirical research by USPTO patent datum to identify that basic research play a more important role for those patented inventions at high level of technology coupling. And the research indicates a positive correlation between patent value and utilization of basic research.
\end{abstract}

\section{Introduction}

At present, enterprises' innovation pattern is undergoing changes profoundly and they acquire various external knowledge resources from other private sectors and public research institutes for technology innovation. At the same time, the innovation model has been transformed from internal research of the enterprise to open cooperation with external public research sectors. But it is difficult to be answered that how does basic research affect patented invention and promote technological progress and innovation and how to better understand the value of basic research for the patented invention.

So, this paper tries to construct a research framework to measure the relationship between basic research and patented invention by quantitative analysis which would combine Fleming's technological invention theory, patent metrics and econometrics model.

\section{Research on Quantitative Measuring Model of the Relationship between Basic Research and Patented Invention}

\section{Framework of Quantitative Measuring Model and Technological Invention Theory}

Fleming constructs the technological invention theory. The theory defines the activity of technological invention as a re-search process on the technical landscape [1], and the re-search results are various according to elevation of each point on technical landscape and interdependent degree between these points [2].

In the framework of technological invention theory, each unique collection of different technical components provides a sole spot in the technological landscape for the inventors' searching. For each collection of technical components, fitness on the technical landscape indicates its utility by re-configuration and combination. On the other hand, utility is an important feature for evaluating the patent value in patent examination process. So the patented inventions with better utility will be located in higher peak point on the technological landscape [3, 4].

\section{Construction of Measuring Model Based on Technological Invention Theory}

Fleming's technological invention theory provides a framework for assessing the importance of basic research to solving the problem in the process of the technological invention. We introduce The Fleming's technological invention theory into the paper to build the measuring model. 
Considering the marketing strategies and economic returns during patent application, the inventors may select their most successful invention for application. So, patent may only represent a higher peak point on technology landscape. The inventors will provide a series of information for patent application, such as technological domain, the number of distribution of technological fields, technologies and scientific knowledge cited by invention, etc. All these rich information provides an observation window of patented invention, and we could establish a quantitative measuring model to identify the role and influence of basic research to patented inventions.

In this paper, we would build a research framework on the relationship among technical difficulty, patent value and degree of dependence of patented invention on basic research, and utilize the patent measure and econometrics methods to measuring the relationship between basic research and patented invention. The empirical research is based on the granted patent from United States Patent and Trademark Office (USPTO).

\section{Measuring Model of Multivariate Analysis of the Negative Binomial Regression}

We introduce the econometric research method, and make a measuring model of multivariate analysis of the negative binomial regression to analysis the relationship between basic research and patented invention from the perspective of quantitative analysis. The research framework is shown in Fig. 1.

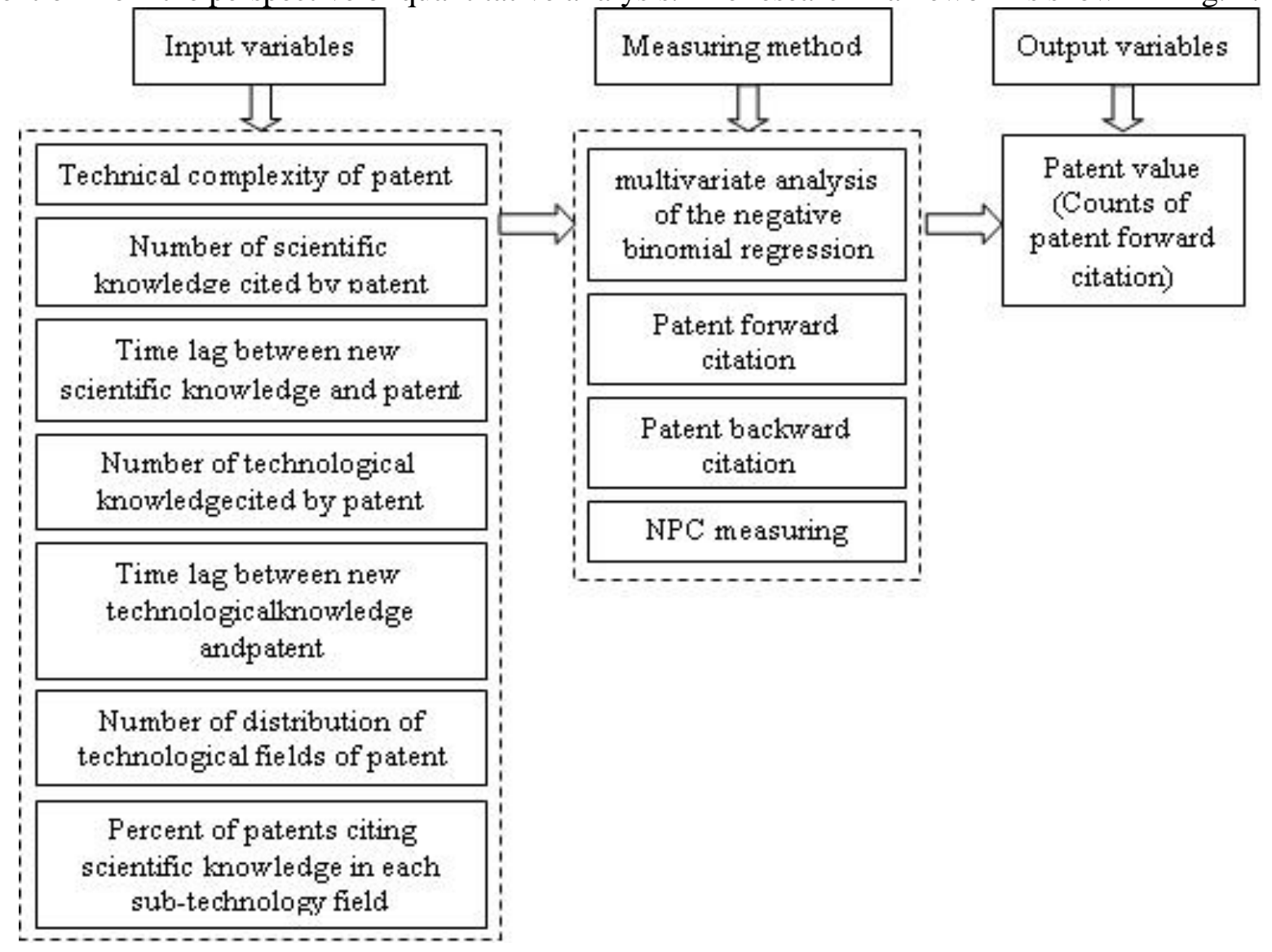

Fig. 1 Research Framework

\section{Patent Metrics}

\section{NPC Method}

In the USPTO patent literature, patent references include three citation types which are citing USPTO patents, citing foreign patents and citing non-patent reference (NPC). NPC contains academic publications, conference papers, books, industry standards and report, etc.

NPC is regarded as a linkage of science and patent in many researches and be used to measure the relationship between basic research and patented invents. Tijssen (2001) [5] indicated that $81 \%$ of the patents who have cited NPC also cited their own scientific fruits from the inventors. NPC method provides 
a reasonable measuring indicator on the impact of science to the patents. And many empirical researches identifies that citing NPC in the process of technological invention helps to improve the patent value.

\section{Technology Coupling}

Fleming's technological invention theory provides the concept of technology coupling of technical components to analysis the difficulty of invention, which is also shown as technical complexity of patented inventions.

The Definition of technology coupling $K i$ : technology coupling refers to the degree of the difficulty of invention when the inventor designs a new patent after searching and re-combining with the sub-technologies on the technical landscape, and the value of technology coupling is defined as $K i$. The value range of $K i$ is $[0,1]$. When $K i$ is more close to 1 , it is more difficult for re-combination of sub-technologies, and the opposite is easier.

The calculation steps of $K i$ are as follows:

Step1: calculating the degree of difficulty of combination between different technical components at the level of technological classification, the value of is $E i$ :

$$
E_{i}=\frac{\begin{array}{c}
\text { Count of subclasses previously } \\
\text { combined with subclass } i
\end{array}}{\text { Count of previous patents in subclass } i}
$$

Step2: calculating $K i$ at the level of the patents:

$$
K_{i}=\frac{\text { Count of subclasses on patent } j}{\sum_{j \in i} E_{i}}
$$

\section{Data Preparation}

We choose the patent database of USPTO as the data resource for the empirical research. The data preparation includes data classification, and the selection, collection and cleaning of data samples.

The empirical research would analysis the relationship between basic research and patented invention from the aspects of different technological fields. So, we should classify the data samples at macro technological domain. We investigate three classification systems from Pavitt [6], NBER [7] and CHI [8], and classify the data sample into four industry categories that are ICT (computer and communication industry \& electronic motor industry), biological medicine (including medical drugs), machinery and chemistry.

For observing the characteristics in different periods of patent data, we choose 45,486 patent samples, and application time of these samples is distributed at each January and February in 1988, 1993 and 1999 (All the patent samples have been granted). Table 1 shows the information of patent samples.

Tab.1 Information of patent samples from USPTO

\begin{tabular}{|c|c|c|}
\hline Year of patent application & Number of patents & Data resource \\
\hline $1988 / 01-1988 / 02$ & 9,496 & \multirow{2}{*}{ Patent database of USPTO } \\
\hline $1993 / 01-1993 / 02$ & 15,575 & \\
\hline $1999 / 01-1999 / 02$ & 20,415 & \\
\hline
\end{tabular}

\section{The Empirical Research of Measuring Model}

\section{Construction of Measuring Model of Multivariate Analysis of the Negative Binomial Regression}

For measuring the relationship between basic research and patent invention by quantitative analysis, we introduce econometric research method and build two models by multivariate analysis of the negative 
binomial regression to analysis to analysis the influence and change pattern of basic research to patented invention.

(1) Measuring model 1

Negative binomial regression equation of measuring model 1 is as follows:

$$
E[y]=e^{\beta_{1} x_{1}+\beta_{2} x_{2}+\beta_{3} x_{3}+\beta_{4} x_{4}+\beta_{5} x_{5}+\beta_{6} x_{6}+\beta_{7} x_{7}}
$$

Taking logarithm for the variables of the equation:

$$
\ln (y)=\beta_{1} x_{1}+\beta_{2} x_{2}+\beta_{3} x_{3}+\beta_{4} x_{4}+\beta_{5} x_{5}+\beta_{6} x_{6}+\beta_{7} x_{7}+\beta_{8} x_{8}
$$

The meaning of each variable in the Eq. 3 and Eq. 4 is as followed table 2:

Tab.2 Meaning of each variable in the equation

\begin{tabular}{|c|c|}
\hline Variable & Meaning \\
\hline Y & Counts of patent's forward citation \\
\hline X1 & Number of scientific knowledge cited by patent \\
\hline X2 & Time lag between new scientific knowledge and patent \\
\hline X3 & Number of technological knowledge cited by patent \\
\hline X4 & Time lag between new technological knowledge and patent \\
\hline X5 & Number of distribution of technological fields of patent \\
\hline X6 & Technology coupling \\
\hline X7 & $(\mathrm{X} 7)^{2}$ \\
\hline X8 & $(\mathrm{X} 7) \mathrm{X}(\mathrm{X} 6)$ \\
\hline $\mathrm{X} 9$ & $(\mathrm{X} 7)^{2} \mathrm{x}(\mathrm{X} 6)$ \\
\hline $\mathrm{X} 10$ & \\
\hline
\end{tabular}

(2) Measuring model 2

Because the Formula (3) builds a basic measure according to the multivariate analysis of the negative binomial regression, it can't be distinguished whether patented invention indeed depends on basic research during the process of technological innovation. So, we construct the second measuring model, as followed Eq. 5.

$$
\ln (y)=\beta_{1} x_{1}+\beta_{2} x_{2}+\beta_{3} x_{3}+\beta_{4} x_{4}+\beta_{5} x_{5}+\beta_{6} x_{6}+\beta_{7} x_{7}+\beta_{8} x_{8}+\beta_{9} x_{9}+\beta_{10} x_{10}
$$

In Eq. 5, variable X9 equals to $(\mathrm{X} 7) \mathrm{x}(\mathrm{X} 6)$, and variable $\mathrm{X} 10$ equals to $(\mathrm{X} 7)^{2} \mathrm{X}(\mathrm{X} 6)$.

\section{The Empirical Analysis}

We use the EViews software to analysis the regression model, and the analysis results for model 1 and model 2 are shown in table 3 to 6.

For comparing with four results of regression analysis, though the variables may be some different in two models, coefficient of the corresponding variable is litter changed which is shown that the model is relative stable.

The variable X2 measures the relationship between patent value and time lag of absorption for scientific knowledge. The results indicate that new knowledge from basic research make more help for improving of patent value.

The variable X4 measures the relationship between patent value and the period of R\&D activities. The results show that a patent would be more opportunities to be cited by other patents when the inventor utilizes new scientific knowledge as soon as possible during the process of invention.

The variables X1 and X3 measure the relationship between patent value and number of scientific and technological (S\&T) knowledge used in patented invention. The two variables are Positive correlate with the number of patent forward citation which indicates that strengthened utilization of S\&T knowledge helps to patent quality. 
Tab.3 Result of empirical research in biological medicine industry

\begin{tabular}{|c|c|c|c|c|}
\hline & \multicolumn{2}{|c|}{ Model1 } & \multicolumn{2}{c|}{ Model2 } \\
\cline { 2 - 5 } & Coefficient & Prob. & Coefficient & Prob. \\
\hline X1 & 0.006 & 0.453 & 0.001 & 0.966 \\
\hline X2 & -0.039 & 0.000 & -0.039 & 0.000 \\
\hline X3 & 0.024 & 0.000 & 0.024 & 0.000 \\
\hline X4 & -0.019 & 0.033 & -0.018 & 0.034 \\
\hline X6 & -0.035 & 0.022 & -0.036 & 0.020 \\
\hline X7 & 0.136 & 0.331 & 0.143 & 0.294 \\
\hline X8 & 0.978 & 0.094 & 1.110 & 0.070 \\
\hline X9 & 1.136 & 0.044 & 1.261 & 0.036 \\
\hline X10 & & & 0.032 & 0.648 \\
\hline Constant & 1.383 & 0.000 & -0.032 & 0.656 \\
\hline Log-likelihood & -2376.458 & & -2376.238 & 0.000 \\
\hline $\mathrm{R}^{2}$ & 0.3116 & & 0.3119 & \\
\hline$N$ & 4731 & & 4731 & \\
\hline
\end{tabular}

Tab.4 Result of empirical research in ICT industry

\begin{tabular}{|c|c|c|c|c|}
\hline & \multicolumn{2}{|c|}{ Model1 } & \multicolumn{2}{c|}{ Model2 } \\
\cline { 2 - 5 } & Coefficient & Prob. & Coefficient & Prob. \\
\hline X1 & 0.005 & 0.671 & 0.013 & 0.373 \\
\hline X2 & -0.015 & 0.302 & -0.015 & 0.293 \\
\hline X3 & 0.018 & 0.000 & 0.018 & 0.000 \\
\hline X4 & -0.043 & 0.000 & -0.043 & 0.000 \\
\hline X5 & 0.005 & 0.862 & 0.005 & 0.867 \\
\hline X6 & 0.297 & 0.070 & 0.304 & 0.068 \\
\hline X8 & 0.790 & 0.202 & 0.833 & 0.198 \\
\hline X9 & 0.966 & 0.091 & 0.994 & 0.096 \\
\hline X10 & & & -0.025 & 0.765 \\
\hline Constant & 1.847 & 0.000 & 0.014 & 0.887 \\
\hline Log-likelihood & -2817.754 & & -2817.67 & 0.000 \\
\hline $\mathrm{R}^{2}$ & 0.2703 & & 0.2712 & \\
\hline$N$ & 4734 & & 4734 & \\
\hline
\end{tabular}

Tab.5 Result of empirical research in machinery industry

\begin{tabular}{|c|c|c|c|c|}
\hline & \multicolumn{2}{|c|}{ Model1 } & \multicolumn{2}{c|}{ Model2 } \\
\cline { 2 - 5 } & Coefficient & Prob. & Coefficient & Prob. \\
\hline X1 & 0.033 & 0.282 & 0.019 & 0.700 \\
\hline X2 & -0.026 & 0.446 & -0.018 & 0.611 \\
\hline X3 & 0.006 & 0.012 & 0.011 & 0.001 \\
\hline X4 & -0.007 & 0.000 & -0.017 & 0.000 \\
\hline X6 & 0.028 & 0.069 & 0.028 & 0.024 \\
\hline X7 & 0.197 & 0.014 & 0.141 & 0.110 \\
\hline X8 & 1.865 & 0.000 & 1.464 & 0.001 \\
\hline X9 & 1.025 & 0.002 & 0.835 & 0.038 \\
\hline X10 & & & 0.120 & 0.546 \\
\hline Constant & 1.864 & 0.000 & -0.209 & 0.289 \\
\hline Log-likelihood & -6378.7 & & 1.866 & 0.000 \\
\hline R & 0.2728 & & -5676.53 & \\
\hline$N$ & 2464 & & 0.2806 & \\
\hline
\end{tabular}


Tab.6 Result of empirical research in chemical industry

\begin{tabular}{|c|c|c|c|c|}
\hline & \multicolumn{2}{|c|}{ Model1 } & \multicolumn{2}{c|}{ Model2 } \\
\cline { 2 - 5 } & Coefficient & Prob. & Coefficient & Prob. \\
\hline X1 & -0.043 & 0.128 & -0.052 & 0.094 \\
\hline X2 & 0.034 & 0.237 & 0.035 & 0.229 \\
\hline X3 & 0.026 & 0.000 & 0.026 & 0.000 \\
\hline X5 & -0.011 & 0.000 & -0.010 & 0.000 \\
\hline X6 & 0.016 & 0.070 & 0.015 & 0.076 \\
\hline X7 & -0.013 & 0.850 & -0.012 & 0.855 \\
\hline X8 & 2.266 & 0.000 & 2.432 & 0.000 \\
\hline X10 & 1.481 & 0.000 & 1.653 & 0.000 \\
\hline Constant & & & 0.056 & 0.469 \\
\hline Log-likelihood & -4835.58 & & -0.060 & 0.497 \\
\hline R & 0.2976 & & -4835.31 & 0.000 \\
\hline$N$ & 3010 & & 0.3023 & \\
\hline Significany & & & 3010 & \\
\hline
\end{tabular}

Note: Significance is 0.05 for the bold numbers in Table3-6.

\section{Conclusions}

The research builds the measuring model of multivariate analysis of the negative binomial regression to explore the relationship between basic research and patented invention. The analysis results indicates that basic research has positive influence to patented invention and help inventors to avoid mistakes during the process of technological innovation. The way of searching for S\&T knowledge would be more direct and efficient. Utilization of basic research will helps to speed the R\&D activities and the abilities of technological innovation and market competition for the enterprises would be enhanced.

\section{Acknowledgments}

This research was supported by ISTIC Key Project Program (Grant No: ZD2015-2) and the National Social Science Fund Project (Grant No: 14BTQ038).

\section{References}

[1] Kauffman, Stuart A, The Origins of Order: Self-Organization and Selection in Evolution, Oxford University Press, New York, 1993.

[2] Fleming L, Explaining the source and tempo of invention: Recombinant learning and exhaustion in technological evolution, Stanford University, 1998.

[3] Fleming L, Recombinant uncertainty in technological search, Management Science. 47(2001) 117-132.

[4] Fleming L, Sorenson O, Technology as a complex adaptive system: evidence from patent data, Research Policy. 30(2001)1019-1039

[5] Hall B H, Jaffe A, Trajtenberg M, Market Value and Patent Citations: A First Look, University of California, Berkely, 2001.

[6] Pavitt K, Sectoral patterns of technical change: toward ataxonomy and a theory, Research Policy. 13(1984) 343-373.

[7] Hall B, Jaffe A, Trajtenberg M, The nber patent citation data file: lessons, insights and methodological tools, Information on http://www.nber.org/papers/w8498, 2001.

[8] Wlash V, Invention and innovation in the chemical industry: demand-pull or discovery-push, Research Policy. 13(1984) 211-234. 